American Journal of Environmental Sciences 4 (3): 198-203, 2008

ISSN 1553-345X

(C) 2008 Science Publications

\title{
Estimation of Vehicle Flows and Emissions for Various Scenarios of Street Network Modifications in Mexico City
}

\author{
Angelica Lozano, Francisco Granados and Juan Pablo Antun \\ Laboratory of Transport and Territorial Systems, Institute of Engineering, \\ National Autonomous University of Mexico. Torre de Ingenieria, \\ Ciudad Universitaria 04510, Mexico DF, Mexico
}

\begin{abstract}
We estimate flows and emissions (NOx, HC, $\mathrm{CO}$ ) generated by vehicles circulating on the main streets of the Mexico City Metropolitan Area. The estimation is made for various scenarios, which include a set of changes to the street network for current and future horizons. These changes encompass the construction of new arcs or improvement of existing arcs. Network flows are estimated by means of a Traffic Assignment Model using a Base Origin-Destination Matrix, generated by sampling and traffic counts. In addition to flows, we obtain speeds and calculate the estimated-flow/capacity ratio for each arc of the network. Emissions for each pollutant are estimated using speed and emission factors obtained from MOBILE Mexico City. Estimated emissions and the estimated-flow/capacity ratio (which is related to congestion) are displayed using a Geographic Information System (GIS). Finally, sets of alternative scenarios are compared and the "best" series of street changes (scenarios) are identified. At this time, one of best scenarios is under construction by the Mexico City Government.
\end{abstract}

Keywords: Metropolitan network, vehicle flow, emission, road infrastructure

\section{INTRODUCTION}

The Mexico City Metropolitan Area covers 50 municipalities belonging to two regions, Distrito Federal (16) and Estado de México (34). Its urban sprawl has an extension of $4,500 \mathrm{~km}^{2}$ or $60 \mathrm{~km}$ per $75 \mathrm{~km}$ and is growing without almost any planning. This metropolis has over 20 million inhabitants and four million registered vehicles, as well as an increasing number of cars per capita ${ }^{[1,2]}$. Additionally, it has a very limited street network, which did not undergo significant improvements over many years. Hence, the Mexico City Metropolitan Area faces serious congestion and air pollution problems (which get worse due its 2,250 meter altitude).

The government of the Distrito Federal (DF) region wanted to decide how to change (to improve) the street network in the short-term.

Any change to the street network could have positive or negative impacts on traffic and congestion ${ }^{[3]}$. Then, before a street can be changed, traffic (and emissions) impact studies are usually required by the municipality. However, most of these studies in Mexico only consider a corridor or surrounding area, without considering that some changes (especially large projects) could impact a bigger area or even the whole metropolitan area ${ }^{[4] .}$

Any proposed change on the streets network usually tries to reduce congestion and emissions, but it is not easy to choose a change from among a set of them.

Hence, we decided to analyze a set of large street changes (most of those proposed by DF Government) and their impacts on traffic and emissions of all of the Mexico City Metropolitan Area municipalities (Costs and budget information was not available).

\section{MATERIALS AND METHODS}

We present an approach to estimate flows and emissions for short-term scenarios consisting of street network changes.

Flow Estimation: Network flows were estimated by means of Traffic Assignment, specifically a User Equilibrium (UE) model and a Geographic Information System for Transportation, GIS-T ${ }^{[5]}$. The UE model assumes that each vehicle (user) tries to minimize its

Corresponding Author: Angelica Lozano, Laboratory of Transport and Territorial Systems, Institute of Engineering, National Autonomous University of Mexico. Torre de Ingenieria piso 2, ala norte,

Cd Universitaria 04510, México DF, México Tel: +52 (55) 56233500 
travel time (cost), without considering its actions or consequences on other users. A stable condition is reached only when no traveler can improve his/her travel time by unilaterally changing his/her route. The objective is to find the link flows, $x$, that satisfy the user-equilibrium criterion when all the origin-destination entries, $\mathrm{q}$, have been appropriately assigned $^{[6]}$. The UE model requires a network, an Origin-Destination (O-D) Matrix and traffic counts.

We created the main street network of the Mexico City Metropolitan Area, consisting of arcs with at least six lanes; this network has 7,983 arcs, 5,776 nodes, 2,425 centroid connector arcs and 1,652 centroid nodes (traffic analysis zones) $^{[7]}$.

Since an O-D Matrix does not exist, a Base O-D Matrix was generated from a sampling applied to 5,000 private car motorists (at home), which were grouped into zones ${ }^{[8]}$. The questionnaire included questions about origins, destinations, schedules and preferred streets. The sampling values were expanded to the population (universe) and the number of trips between each origin-destination pair, were obtained for the rush $\operatorname{hour}^{[7,9]}$.

Rush hour traffic counts (215) (between 8:00 am and 9:00am of a normal weekday) were used.

Vehicular flows were estimated for the rush hour. These flows were used to calculate estimatedflow/capacity ratio for each arc of the network for certain values. This ratio could be an approximation to congestion.

Emissions Estimation: We estimated oxides of nitrogen (NOx), carbon monoxide (CO) and hydrocarbon (HC) generated on each arc of the network during the rush hour. Estimated emissions on each arc were obtained as shown in Eq. (1), where $E_{a p}$ is the estimated tons of pollutant $\mathrm{p}$ produced on arch a during rush hour; Flow ${ }_{\mathrm{a}}$ is the estimated number of vehicles on arc a during the rush hour; $\mathrm{L}_{\mathrm{a}}$ is the length $(\mathrm{km})$ of arc a (obtained from a GIS); $\mathrm{EF}_{\mathrm{ap}}$ is the emission factor of pollutant $\mathrm{p} \quad\left(\mathrm{g} \mathrm{km}^{-1}\right.$ vehicle), obtained from MOBILE $^{[10]}$ using the estimated speed on arc a (during the rush hour).

$$
\mathrm{E}_{\mathrm{ap}}=\frac{\left(\text { Flow }_{\mathrm{a}} \mathrm{L}_{\mathrm{a}} \mathrm{EF}_{\mathrm{ap}}\right)}{1 \times 10^{6}}
$$

Emissions factors were calculated by means of MOBILE, which sets a factor ( $\mathrm{g} / \mathrm{km}$ vehicle) based on vehicle characteristics (speed, weight, type of fuel, driving conditions) and environmental characteristics (environmental temperature and season of the year) ${ }^{[11]}$.
We used environmental characteristics that are typical in the winter season in Mexico City and vehicle characteristics applicable to average fleet circulating at the estimated speed on arc a (which were obtained by means of traffic assignment).

Scenarios generation: We generated various scenarios, the current one and short-term scenarios. Generating the current scenario required current traffic counts and the estimated base O-D matrix. Scenarios which included changes in the street network, also required the changed network according to future projects. Future scenarios required projections of traffic count and base O-D matrix. Projections were based on the potential increase of vehicular movement in each sub-area of the Mexico City Metropolitan Area. This increase was obtained based on demographic, socioeconomic, vehicular fleet and urban sprawl growth information. Specifically, for each sub-area, the following information was obtained and analyzed: a) population density, population growth rate and estimated future population ${ }^{[12]}$; b) current and estimated future vehicle fleet; c) current and estimated future number of vehicles per capita; d) current and estimated future active population (employed people); e) current land use and urban development plans (including urban reserve zones) and f) current urban sprawl and expected legal and illegal growth thereof.

Sub-areas were classified according to their type on the land use plans. We assumed that the urban development plans would be undertaken (which could not happen in developing countries). However, we also considered areas, not included in the urban development plans, such that could be incorporated into the urban sprawl (due to the illegal or unplanned growth of urban sprawl).

Vehicles per capita per sub-area were estimated, based on the information previously described, according to its sub-area type and the year in the future. The potential increase of vehicular movement into each sub-area was based on the estimated future number of vehicles in the sub-area and the sub-area type ${ }^{[7]}$.

\section{RESULTS AND DISCUSSION}

Sub-areas of the Mexico City Metropolitan Area were grouped depending on their potential increase of vehicular movement. Figure 1 shows municipalities, grouped in downward order according to their potential increase in vehicular movement.

It is interesting to note that two very different areas could have the same potential increase in vehicular movement, but this rate could be due to two different 
reasons. For instance, a very poor zone in the outskirts of the metropolis could have the same rate as a high welfare zone near downtown, where the population is decreasing and the number of cars per capita is high.

Between groups 1 and 7, there is a series of shades. Group 1 areas have the highest potential increase in vehicular movement. Currently, these areas have few vehicles, but high demographic growth is expected along with significantly expanded urban sprawl. Group 3 areas have few vehicles and an expected high demographic growth, but their urban sprawl is not expected to expand significantly. Group 7 areas have the lowest potential increase in vehicular movement; insignificant land use changes and demographic and vehicular growth are expected in these areas.

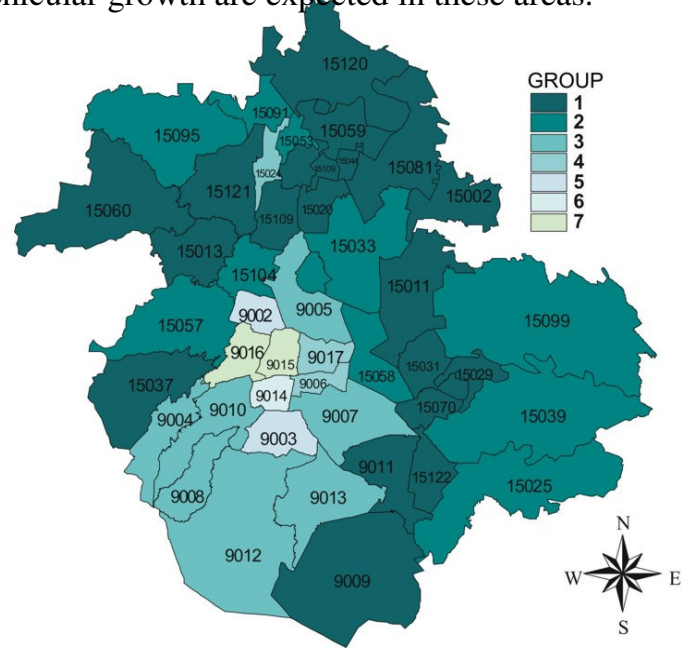

Fig. 1: Municipalities of the Mexico City Metropolitan Area, classified in downward order according to their potential increase of vehicular movement (The numbers in the municipalities are their official ID)

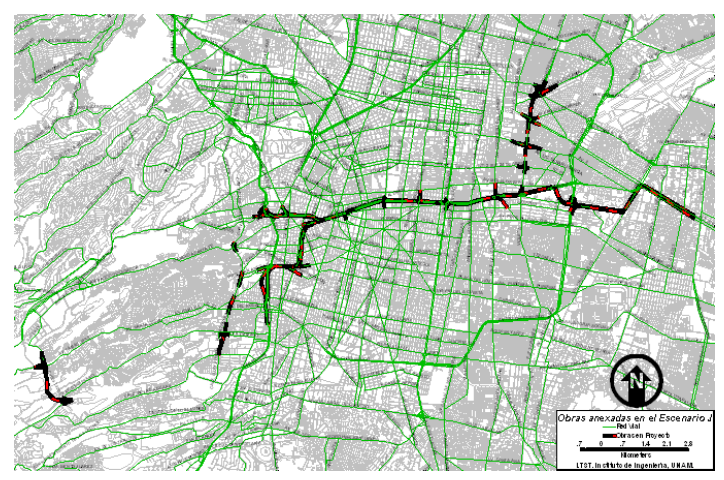

Fig. 2: Network changes of Scenario J; main network is in green color and new arcs are in red-black lines

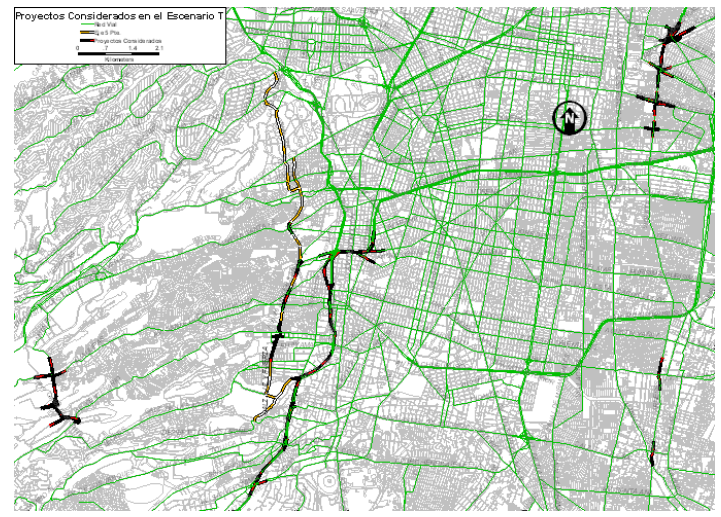

Fig. 3: Network changes of Scenario T; main network is in green color, new arcs are in red-black lines and improved existent arcs are in yellow-white lines

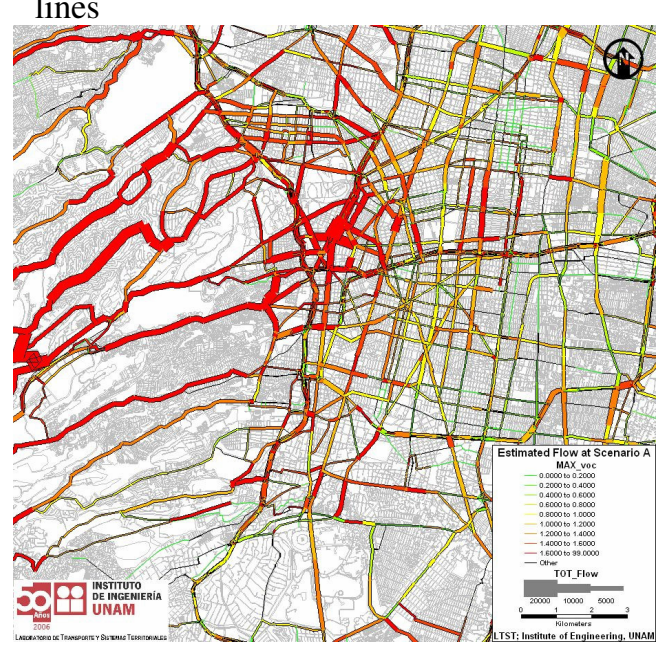

Fig. 4: Estimated flows for Scenario A. Arc width represents flow and range of colors indicates congestion, from free flow (green) to congestion with queue (red) ${ }^{[9]}$

A set of 22 scenarios were generated and analyzed, including the current one and 21 scenarios representing short-term (one and two years from now) network changes. As an example, changes in the street network for Scenarios $\mathrm{J}$ and $\mathrm{T}$ are shown in Fig. 2 and 3, respectively.

Flows and emissions were estimated for each arc of the network and for each scenario. Maps were used for representing estimated (rush hour) flows and emissions. Figure 4 and 5 show estimated flows for Scenarios A and $\mathrm{V}$, respectively, in the central zone of the Mexico City Metropolitan Area. Flow is represented through 
arc width, while estimated-flow/capacity ratio (which gives approximate congestion) is represented by means of colors, from green to red, where red indicates queue. It is easy to see that Scenario $\mathrm{V}$ is better than $\mathrm{A}$. However, visual comparison of scenarios is usually difficult. In certain zones, scenario-1 congestion could be lower than scenario-2 congestion, but scenario-1 congestion could be higher in other zones.

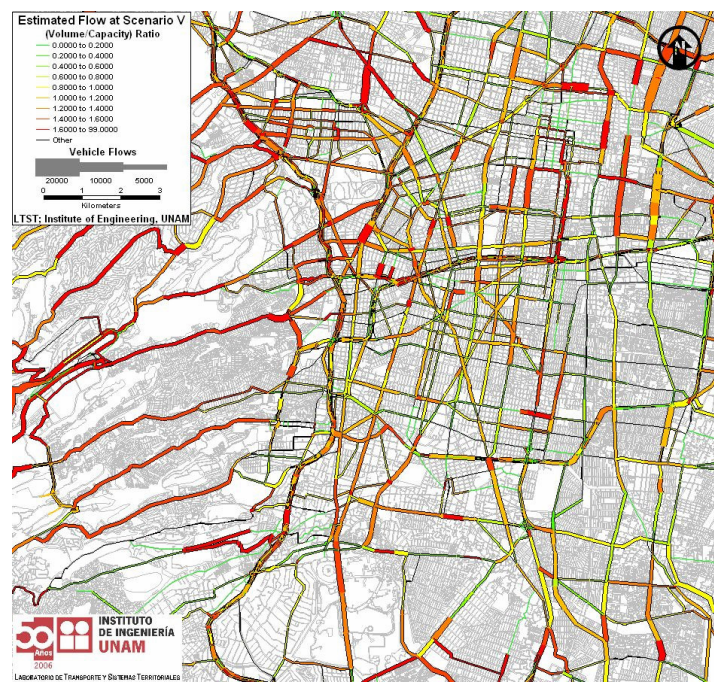

Fig. 5: Estimated flows for Scenario V. Arc width represents flow and range of colors indicates congestion, from free flow (green) to congestion with queue (red) $)^{[9]}$

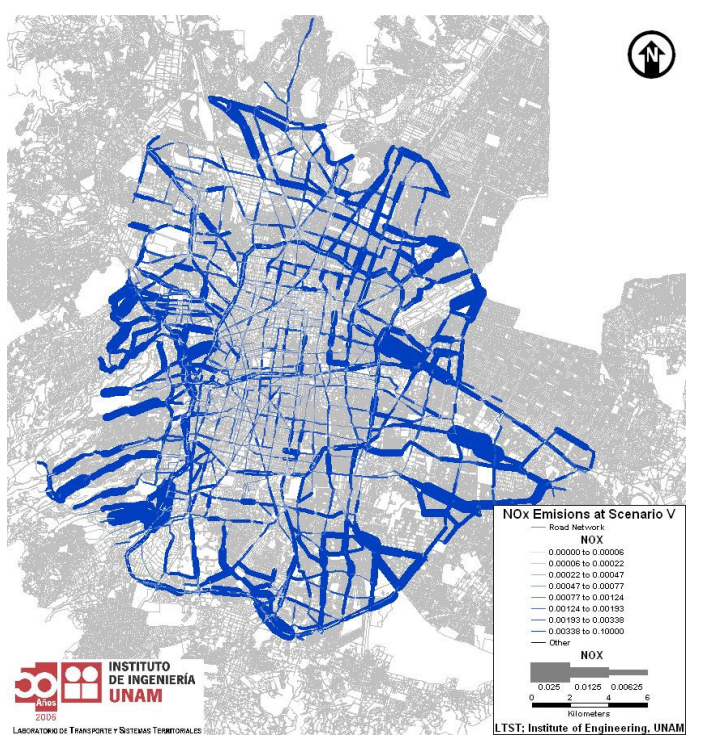

Fig. 6: Estimated emissions of NOx (oxides of nitrogen), for Scenario V. Arc width represents quantity of emissions ${ }^{[9]}$
Emissions of NOx, $\mathrm{CO}$ and $\mathrm{HC}$ were estimated for each scenario and for each arc of the central network. Regrettably, there was not enough information (traffic counts) for the outskirts of the Mexico City Metropolitan Area, even when their flows were estimated. Figure 6 shows NOx emissions in the central network for Scenario V.

Given that visual emissions comparison is difficult, total tons of emissions (in the central network) were obtained in order to compare scenarios. For each pollutant, total emissions are the sum of emissions in all of the arcs of the central network. Table 1 shows the total tons of $\mathrm{NOx}, \mathrm{CO}$ and $\mathrm{HC}$ for some scenarios.

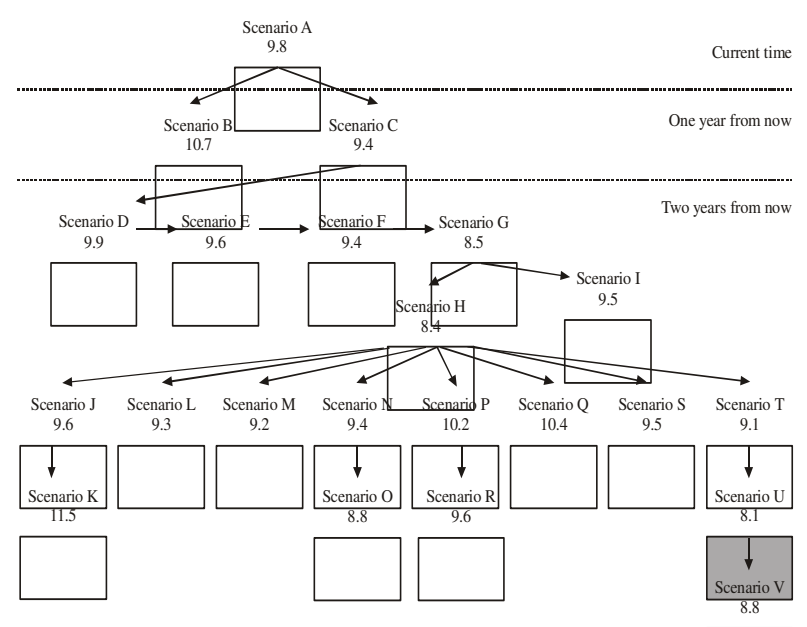

Fig. 7: Total estimated tons of NOx, for the rush hour, in the main network of the central network of the Mexico City Metropolitan Area, for each scenario

Each time that a new scenario was generated, estimated flows, congestion and emissions were analyzed and such a scenario was compared with previously generated scenarios.

The objective was to choose the best changes from among a set of potential changes to the network. The Distrito Federal Government decided that the best change would be such that could produce the greatest decrease of emissions in comparison to Scenario A (which represented the current situation) and NOx would be the most significant pollutant.

Scenarios were generated following the tree structure shown in Fig. 7. Scenario A represents the current situation, whereas Scenarios B and C represent next year's situation, respectively, whether or not a 
Table 1: Estimated total tons of Hydrocarbons (HC), Monoxide of Carbon (CO) and Oxides of Nitrogen (NOx) for some scenarios during the rush hour in the central network of the Mexico City Metropolitan Area ${ }^{[9]}$

\begin{tabular}{llcr}
\hline Scenario & HC & CO & NOx \\
\hline A & 22.6 & 231.1 & 9.8 \\
B & 26.2 & 266.9 & 10.7 \\
C & 19.6 & 198.3 & 9.4 \\
G & 16.8 & 168.9 & 8.5 \\
H & 15.5 & 156.1 & 8.4 \\
K & 28.7 & 290.1 & 11.5 \\
O & 15.9 & 160.2 & 8.8 \\
Q & 24.0 & 242.9 & 10.4 \\
U & 13.6 & 137.1 & 8.1 \\
V & 17.5 & 176.8 & 8.8 \\
\hline
\end{tabular}

significant new street is built. Furthermore, Scenarios from $\mathrm{D}$ to $\mathrm{V}$ represent situations two years from now, with different changes in the street network.

For Scenarios D to V, each child scenario share the set of changes included in its parent scenario and has an additional and particular change which is different to the changes of their brother scenarios.

Scenarios G, H, O, U and V have the best flow circulation and the lowest estimated tons of emissions. According to $\mathrm{HC}$ and $\mathrm{CO}$ emissions, the ranking of the best scenarios is $\mathrm{U}, \mathrm{H}, \mathrm{O}, \mathrm{G}$ and $\mathrm{V}$; however, according NOx emissions, this ranking is $\mathrm{U}, \mathrm{H}, \mathrm{G}$ and $\mathrm{O}$ and $\mathrm{V}$. Therefore, the best is Scenario $\mathrm{U}$ and second place is for Scenario $\mathrm{H}$.

\section{CONCLUSIONS}

General conclusions and reflections are the following:

- The proposed procedure is focused on short-term scenarios. Additional information (such as an O-D matrix obtained by conventional methods) and other procedures are required for long-term scenarios.

- The obtained information on flows, congestion and emissions is very useful for helping decisionmakers to determine how to change a metropolitan street network, in order to improve its flow and reduce emissions.

- However, the differences between some scenarios were relatively small, reason why budget and additional criteria must be considered for making a decision. These criteria could be quantitative (such as cost) and qualitative (such as urban image impacts). Lately, some works are oriented to a multi-criteria analysis based upon judging over appropriate weighted criteria indicators ${ }^{[13]}$.
- The application of the proposed procedure to the Mexico City Metropolitan Area has allowed identify the best modifications to the network for the short-term, according to two criteria: flow and emissions and identify those changes that must be avoided. However decision takers consider additional criteria (cost, budget, social impacts, etc.), whose information is not available for us. At this time, one of the best scenarios is being built by the Mexico City Government (Distrito Federal Government), but given the confidentiality of this project, we can not describe it.

\section{ACKNOWLEDGMENTS}

This project had financial support from the Distrito Federal Government. The authors thank Vicente Torres for his valuable technical assistance.

\section{REFERENCES}

1. INEGI, 2000. Statistics of the Mexico City Metropolitan Zone. Instituto Nacional de Estadística Geografía e Informática, INEGI), México (In Spanish).

2. GEM - Secretaría de Desarrollo Metropolitano, 2000. Basic data of 28,34 y 58 urban municipalities of the Estado de México, Gobierno del Estado de México (GEM) (In Spanish).

3. Nagurney, A., 2000. Congested urban transportation networks and emission paradoxes. Transport. Res. Part D 5: 145-151.

4. Lozano, A., J.P. Antún and V. Torres, 2005. Determination of the modifications for a metropolitan street network: an analysis approach and two applications in Mexico. Proceedings of the Ninth international conference in Computers in Urban Planning and Urban Management (CUPUM 05 ), London UK, June 29 - July $1^{\circ}$.

5. TransCAD, 2002. User's Guide TransCAD Transportation GIS Software, Caliper Corporation, US.

6. Sheffi, Y., 1985. Urban transportation networks: equilibrium analysis with mathematical programming methods, Prentice Hall, New Jersey.

7. Lozano, A., F. Granados, V. Torres, R. Hernández, A. Guzmán, R. Alarcón and J.P. Antún, 2002. Macroscopic simulation of the effect, of a second level on Periférico and Viaducto streets, on the traffic of the Mexico City Metropolitan Zone (Fase I). Technical Report for Mexico City (Distrito Federal) Government, Instituto de Ingeniería, UNAM, Mexico. pp: 171 (In Spanish). 
8. Lozano, A., J.P. Antún and F. Granados, 2004. Statistical results of origin-destination sampling of private cars, in the Mexico City Metropolitan Zone. Technical Report for Mexico City (Distrito Federal) Government. Instituto de Ingeniería, UNAM. pp: 15 (In Spanish).

9. Lozano, A., V. Torres, A. Guzmán, F. Granados, L. Álvarez-Icaza, R. Magallanes and J.P. Antún, 2004. Macroscopic simulation of the effect, of a second level on Periférico and Viaducto streets, on the traffic of the Mexico City Metropolitan Zone (Fase II). Technical Report for Mexico City (Distrito Federal) Government, Instituto de Ingeniería, UNAM, Mexico, pp: 125 (In Spanish).

10. EPA, 2000. Mobile 5-Mexico: Documentation and User's Guide. Environmental Protection Agency (EPA) US.
11. Perrusquia, M., 1998. Discusión del Modelo Computacional Mobil 5a.3 para la Determinación de Factores de Emisión de Contaminantes Emitidos por Vehículos Automotores de la ZMCM. Thesis (chemical industrial engineering), Instituto Politécnico Nacional, México.

12. CONAPO, 2000. Demographic and urban scenarios for the Mexico City Metropolitan Zone, 1990-2010. Consejo Nacional de Población, (CONAPO), México (In Spanish).

13. Arampatzis, A., C. Kiranoudis, P. Scaloubacas and D. Assimacopoulos, 2004. A GIS-based decision support system for planning urban transportation policies. Eur. J. Operat. Res., 152: 465-475. 